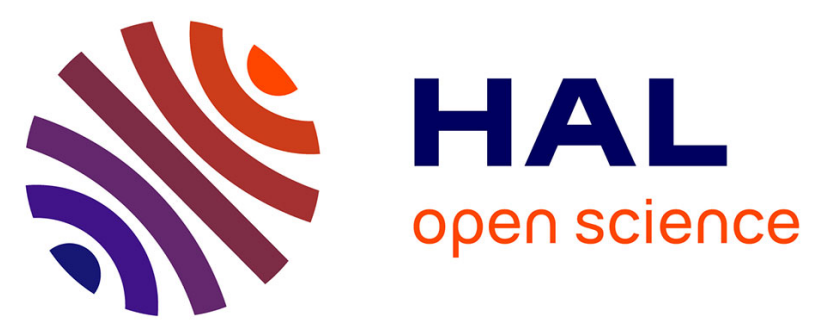

\title{
Accelerated intestinal transit in inbred mice with an increased number of interstitial cells of Cajal
}

Sylvain S. Bellier, Nelly R. da Silva, Geneviève Aubin-Houzelstein Aubin

Houzelstein, Colette Elbaz, Jean-Marie Vanderwiden, Jean-Jacques J.-J. Panthier

\section{To cite this version:}

Sylvain S. Bellier, Nelly R. da Silva, Geneviève Aubin-Houzelstein Aubin Houzelstein, Colette Elbaz, Jean-Marie Vanderwiden, et al.. Accelerated intestinal transit in inbred mice with an increased number of interstitial cells of Cajal. AJP - Gastrointestinal and Liver Physiology, 2005, 288, pp.G151-G158. hal-02681832

\section{HAL Id: hal-02681832 \\ https://hal.inrae.fr/hal-02681832}

Submitted on 31 May 2020

HAL is a multi-disciplinary open access archive for the deposit and dissemination of scientific research documents, whether they are published or not. The documents may come from teaching and research institutions in France or abroad, or from public or private research centers.
L'archive ouverte pluridisciplinaire HAL, est destinée au dépôt et à la diffusion de documents scientifiques de niveau recherche, publiés ou non, émanant des établissements d'enseignement et de recherche français ou étrangers, des laboratoires publics ou privés. 


\title{
Accelerated intestinal transit in inbred mice with an increased number of interstitial cells of Cajal
}

\author{
Sylvain Bellier, ${ }^{1}$ Nelly R. Da Silva, ${ }^{1}$ Geneviève Aubin-Houzelstein, ${ }^{1}$ Colette Elbaz, ${ }^{1}$ \\ Jean-Marie Vanderwinden, ${ }^{2}$ and Jean-Jacques Panthier ${ }^{1}$ \\ ${ }^{1}$ Unité Mixte de Recherche 955 Institut National de Recherche Agronomique-Ecole Nationale Vétérinaire \\ d'Alfort de Génétique Moléculaire et Cellulaire, Ecole Nationale Vétérinaire d'Alfort, France; and \\ ${ }^{2}$ Laboratoire de Neurophysiologie, Faculté de Médecine, Université Libre de Bruxelles, Belgium
}

Submitted 28 January 2004; accepted in final form 28 July 2004

\begin{abstract}
Bellier, Sylvain, Nelly R. Da Silva, Geneviève Aubin-Houzelstein, Colette Elbaz, Jean-Marie Vanderwinden, and JeanJacques Panthier. Accelerated intestinal transit in inbred mice with an increased number of interstitial cells of Cajal. Am J Physiol Gastrointest Liver Physiol 288: G151-G158, 2005. First published August 5, 2004; doi:10.1152/ajpgi.00048.2004.-The interstitial cells of Cajal (ICC) play an important role in coordinating intestinal motility, and structural alterations in ICC are found in several human digestive diseases. Mouse models with defects in ICC allow a better understanding of their functions. We investigated the pattern of intestinal motility and the distribution of ICC in the PRM/Alf inbred mouse strain, characterized by a selective intestinal lengthening. In $\mathrm{PRM}$ /Alf mice, the digestive transit time, evaluated by using thermophilic Bacillus subtilis spores, was normal, indicating accelerated transit. The contractility and slow-wave frequency, recorded on isolated segments from the proximal small intestine, were significantly increased. The number of ICC was also significantly higher along the small intestine and the colon. The concomitant increase of the contractility, the slow-wave frequency, and the number of ICC is consistent with the proposal of a role of ICC number increase in the higher intestinal transit speed. The PRM/Alf model should be useful to further investigate the roles of ICC in the control of digestive motility.

gut length; kit receptor; electrical slow waves; gastrointestinal motility; genetic model
\end{abstract}

INTRINSIC AND EXTRINSIC NEUROHUMORAL signals control intestinal motility. An essential part of the system is the electrical pacemaker activity that originates in interstitial cells of Cajal (ICC). These cells are present in close association with smooth muscle cells and neurons of the gastrointestinal tract. In the mouse, ICC are fully differentiated at weaning, when the animals are given adult diet (13). The possible role of ICC in coordinating the contractile activity of the intestine has come to light in recent years $(17,38)$. Alterations of ICC were reported in a variety of gastrointestinal disorders, including hypertrophic pyloric stenosis $(24,35,41)$, Hirschsprung's disease (37, 42, 43), and intestinal pseudo-obstructions (19, 21, 44). Study of mouse models has proven to be a valuable strategy for studying the cause-and-effect relationship between ICC and motility problems, and Kit/W and SCF/Steel mutant mice have been instrumental in the study of the physiological roles of ICC (reviewed in Ref. 30). The Kit signaling pathway is essential for the development and maintenance of ICC (26). Both Kit and Steel mutant mice exhibit absence of electrical rhythmicity

Address for reprint requests and other correspondence: S. Bellier, UMR 955 INRA-ENVA de Génétique Moléculaire et Cellulaire, Ecole Nationale Vétérinaire d'Alfort, 7 Ave. du Général De Gaulle, 94704 Maisons-Alfort Cedex, France (E-mail: sbellier@vet-alfort.fr). (i.e., slow waves) associated with underdevelopment of certain classes of ICC, including ICC of the small intestine that lie in the plane of the myenteric plexus (ICC-MP) between the circular and longitudinal muscle layers $(17,38,39)$. The absence of ICC and slow waves in the small intestine of Kit mutant mice was paralleled with altered peristaltic movements of intestinal contents (10). However, it remains difficult to predict how abnormalities in ICC could influence digestive motor activity in vivo, because peristalsis is controlled by multiple, simultaneously operating mechanisms, in particular within the enteric nervous system (34). Indeed, migrating motor complexes can be recorded in the small intestine even when the ICC-MP are largely missing and slow waves are consequently absent (32). Further studies are required to determine the exact contribution of ICC to the digestive motor activity.

We describe here a new mouse model that should prove useful for studying digestive motor mechanisms. The PRM/Alf strain was derived from mice of unknown genetic background, and it carries the recessive coat color mutation patchwork (2, 4). PRM/Alf mice were recently shown to exhibit a hereditary increase in intestine length (3). Here we have investigated the distribution of ICC and the pattern of digestive motility in the $\mathrm{PRM}$ /Alf strain, compared with two classical, inbred strains, $\mathrm{DBA} / 2 \mathrm{~J}$ and $129 \mathrm{~S} 2 / \mathrm{SvPa}$ (hereafter referred to as 129S2).

\section{MATERIALS AND METHODS}

Animals. Mice from the DBA/2J and 129S2 inbred strains were obtained from Charles River Laboratories (Saint-Aubin-Les-Elbeuf, France) and Institut Pasteur (Paris, France), respectively. Mice homozygous for the patchwork mutation $(2,4)$ were obtained from Karen Moore (National Cancer Institute, Frederick, MD) and an inbred strain, called PRM/Alf, was derived by $>30$ successive brother-

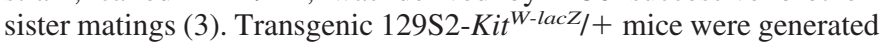
in our laboratory. These mice carry the Escherichia coli lacZ gene inserted in place of the first exon of the Kit gene (5). The presence of a wild-type $(+)$ Kit allele allows $K i t^{W-l a c Z} /+$ heterozygous mice to develop normally, whereas the $l a c Z$ reporter gene allows identification of the Kit-expressing cells by the $\beta$-galactosidase (X-gal) histochemical reaction. The pattern of Kit-expressing cells in $129 \mathrm{~S} 2-\mathrm{Kit}^{\mathrm{W}-\mathrm{lac} Z} /+$ heterozygous mice is identical to that of Kit-immunoreactive cells in 129S2 wild-type $\left(\mathrm{Kit}^{+/+}\right)$mice (36). PRM/Alf mice heterozygous for the $K i t^{W-l a c Z} /+$ allele were generated by mating PRM/Alf mice and 129S2-Kit ${ }^{\text {W-lacZ}} /+$ mice. The progeny were repeatedly back-crossed onto the PRM/Alf background and selected for the Kit ${ }^{W-l a c Z} /+$ allele.

\footnotetext{
The costs of publication of this article were defrayed in part by the payment of page charges. The article must therefore be hereby marked "advertisement" in accordance with 18 U.S.C. Section 1734 solely to indicate this fact.
} 
At the 10th generation, i.e., after nine backcrosses, PRM/Alf $\cdot 129 \mathrm{~S} 2$ $\mathrm{Kit}^{\mathrm{W} \text {-lacZ} /}+$ mice could be estimated to be identical to PRM/Alf mice for $>99.8 \%$ of their genome. These mice will hereafter be referred to as congenic PRM/Alf-Kit ${ }^{\text {W-lacZ/H. }}$.

Animals were fed ad libitum with standardized mouse pellet food (formula A03; Usine d'Alimentation Rationnelle, Rennes, France). They were housed and bred under identical conditions and euthanized by $\mathrm{CO}_{2}$ inhalation, in accordance with the principles and guidelines of the Ecole Nationale Vétérinaire d'Alfort on animal welfare. Threemonth-old male mice were used.

Histology of the intestine. The intestines of PRM/Alf and DBA/2J mice ( $n=3$ and $n=4$, respectively) were removed, and 1-cm-long samples were harvested from the proximal small intestine $(2 \mathrm{~cm}$ after the pylorus), the distal small intestine $(2 \mathrm{~cm}$ before the ileocecal junction), the proximal colon (1 cm after the ileocecal junction), and the distal colon ( $1 \mathrm{~cm}$ from the anus). Samples were fixed for $48 \mathrm{~h}$ in $10 \%$ formalin in PBS, embedded in paraffin, and sectioned at $4 \mu \mathrm{m}$. Sections were deparaffinized in toluene, rehydrated, and stained with hematoxylin-eosin-saffron. Sections were viewed under a Leica (Rueil-Malmaison, France) bright-field microscope. The Leica imaging system (QWin software) was used for morphometric analysis. For each sample, at least four measurements per section were made on a minimum of five nonadjacent sections.

Quantification of Kit-expressing ICC in congenic PRM/AlfKit ${ }^{W-\text { lacZ }} /+$ and 129 S2-Kit ${ }^{W-l a c Z} /+$ mice. Intestine samples were harvested as above from four congenic PRM/Alf-Kit ${ }^{W-l a c Z} /+$ and four $129 \mathrm{~S} 2-\mathrm{Kit}^{\mathrm{W}-\mathrm{lac} Z} /+$ mice and fixed for $60 \mathrm{~min}$ in $4 \%$ (vol/vol) paraformaldehyde in PBS. X-gal histochemistry was performed as previously reported (5). Sections (4 $\mu \mathrm{m}$ thick) were then counterstained with hematoxylin and eosin and mounted with Eukitt. For each sample, $\mathrm{X}$-gal-positive cells in the entire circumference were counted on five nonadjacent sections, using a $\times 20$ objective. In the small intestine, ICC lie in the myenteric region between the circular and longitudinal muscle layers (ICC-MP) and at the inner surface of the deep muscular plexus (ICC-DMP). In the colon, ICC are found at the subserosa (ICC-SS), around the myenteric plexus (ICC-MP), in the circular muscle layer (ICC-CM), and at the border between the submucosa and the circular muscle layer (ICC-SMP). Their relative distribution in each location (proximal and distal small intestine, proximal and distal colon) was calculated as their mean numbers on two nonadjacent entire transverse sections divided by the mean number of total X-galpositive cells, i.e., ICC-MP+ICC-DMP in the small intestine or ICC-SS+ICC-MP+ICC-CM+ICC-SMP in the colon.

Extracellular slow-wave recording on isolated proximal small intestine segments. Ten PRM/Alf and seven DBA/2J mice were used. A 5-cm segment of proximal small intestine with the pylorus attached was excised and pinned without tension on the bottom of a 5-ml water-jacket bath coated with Sylgard (Dow Corning, Midland, MI) at $37 \pm 0.5^{\circ} \mathrm{C}$ and bathed at $2 \mathrm{ml} / \mathrm{min}$ with warmed modified Krebs solution (in mM: $125 \mathrm{NaCl}, 5 \mathrm{KCl}, 2.5 \mathrm{CaCl}_{2}, 1.2 \mathrm{MgCl}_{2}, 1.2$ $\mathrm{NaH}_{2} \mathrm{PO}_{4}, 4 \mathrm{NaHCO}_{3}, 11$ glucose, and 10 HEPES) aerated with $95 \%$ $\mathrm{O}_{2}-5 \% \mathrm{CO}_{2}$. Slow-wave activity was recorded with a serosal $\mathrm{Ag} / \mathrm{AgCl}$ suction electrode $(6,10,16,33) 2 \mathrm{~cm}$ distal to the pylorus for a minimum of 15 min. The electric signal was amplified on a Duo 773 electrometer (World Precision Instruments, Sarasota, FL) and digitalized on a PC with an Acknowledge-MP100 Biopac system (World Precision Instruments). Slow waves were counted on trace printouts, and their average frequency was determined over the recording period.

Mechanical activity recording on isolated proximal small intestine segments. Three PRM/Alf and three DBA/2J mice were used. A segment of the proximal small intestine $(1 \mathrm{~cm}$ in length) was excised from each animal and placed vertically in a 20-ml water-jacket bath (LO1 compact multichamber organ bath; Bioseb, Chaville, France). Tissues were bathed with modified Krebs solution aerated with $95 \%$ $\mathrm{O}_{2}-5 \% \mathrm{CO}_{2}$ and maintained at $37 \pm 0.5^{\circ} \mathrm{C}$. The intestines were allowed to equilibrate for at least $30 \mathrm{~min}$, during which time they were subjected to slight tension just sufficient to remove slack in the apparatus. Tension generated along the longitudinal axis of the intestine was recorded with a force-displacement transducer (Biopac, Santa Barbara, CA), amplified with DA100B amplifier, and visualized with the Acknowledge-MP100 system.

Estimation of the gastrointestinal transit time. Four PRM/Alf and four DBA/2J fasted mice were force fed with $0.4 \mathrm{ml}$ of a water solution containing $22 \times 10^{6}$ spores of a strictly aerobic and thermophilic Bacillus subtilis strain as an inert transit marker $(8,12,29)$. All feces were collected after 2, 3, 4, 5, 6, 7, 8, 9, 10, and $24 \mathrm{~h}$. Aqueous fecal slurries were prepared, diluted appropriately, spread on nutrient agar plates, and incubated at $65^{\circ} \mathrm{C}$ for $24 \mathrm{~h}$. Thermophilic Bacillus subtilis spores germinated at $65^{\circ} \mathrm{C}$ to produce small, white colonies. No other thermophiles could be consistently cultured from feces under these conditions. From Bacillus subtilis concentrations, the mean transit time (in hours) through the whole intestine was calculated as $\sum\left(\mathrm{m}_{\mathrm{i}} \mathrm{t}_{\mathrm{i}}\right) / \sum \mathrm{m}_{\mathrm{i}}$, where $\mathrm{m}_{\mathrm{i}}$ is the number of spores present in the feces passed at time interval $t_{i}(27)$. The recovery of the transit marker (range $=50-97 \%$ ) was satisfactory, considering the partial regurgitation that occasionally occurred during force feeding.

Measurement of gastric emptying and transit. Ten PRM/Alf and nine DBA/2J fasted mice were force fed with $0.1 \mathrm{ml}$ of a semiliquid solution containing Evans blue (5\% Evans blue in $0.9 \% \mathrm{NaCl}$ with $0.5 \%$ methylcellulose). Fifteen minutes later, they were anesthetized and a laparotomy was performed. The stomach was rapidly clamped above the lower esophageal sphincter and beneath the pylorus to prevent leakage of Evans blue. The stomach was then cut just beneath the clamps. Gastric emptying was determined spectrophotometrically (11). Briefly, the stomach and its contents were put in $15 \mathrm{ml} 0.1 \mathrm{~N}$ $\mathrm{NaOH}$, minced, and homogenized. After dilution to a volume of $20 \mathrm{ml}$ with $0.1 \mathrm{~N} \mathrm{NaOH}$, samples were kept at room temperature for $1 \mathrm{~h}$. Then $5 \mathrm{ml}$ supernatant was collected and centrifuged at 2,500 rpm during $20 \mathrm{~min}$ at $4^{\circ} \mathrm{C}$. Samples were further diluted, and the absorbance was read at a wavelength of $565 \mathrm{~nm}$ (A565). The stomach and its contents obtained from a mouse killed immediately after orogastric administration of Evans blue served as standard (reference stomach). The percentage of gastric emptying was calculated by the formula [(A565 reference - A565 sample)/A565 reference] $\times 100$.

Statistics. Statistical analyses were performed with the StatView F-4.51.3.PPC software (Abacus Concepts, Berkeley, CA). Data are expressed as means \pm SE. Distribution normality was tested by comparing the observed distribution to a normal distribution with the same mean and standard deviation and use of a Kolmogorov-Smirnov test. Variances were compared with an $F$-test. Statistical differences were tested using a Student's $t$-test or a multivariate analysis of variance (MANOVA). For not normally distributed values, or values with unequal variances, a Mann-Whitney $U$-test was used. $P$ values $<0.05$ were considered statistically significant.

\section{RESULTS}

Morphometric analysis of the PRM/Alf mouse intestine. $\mathrm{PRM} /$ Alf mice exhibited an obvious abdominal distention (Fig. 1). This feature is a consequence of increased intestinal length in PRM/Alf mice (3). The intestine of PRM/Alf adult mice of both sexes showed, on average, a $30 \%$ increase in length when compared with $129 \mathrm{~S} 2$ adult mice $(74.8 \pm 0.8 \mathrm{~cm}$ in 42 $\mathrm{PRM}$ /Alf mice compared with $57.6 \pm 0.5 \mathrm{~cm}$ in $43129 \mathrm{~S} 2$ mice) and DBA/2J (3) adult mice. The difference in intestine length being much more pronounced between PRM/Alf and $\mathrm{DBA} / 2 \mathrm{~J}$ mice, we used the latter strain in a morphometric analysis. To check whether the intestine lengthening is associated with an enlargement, we measured the small and large intestine circumference in both the proximal and distal parts (Fig. 2). Proximal and distal small intestine circumferences 


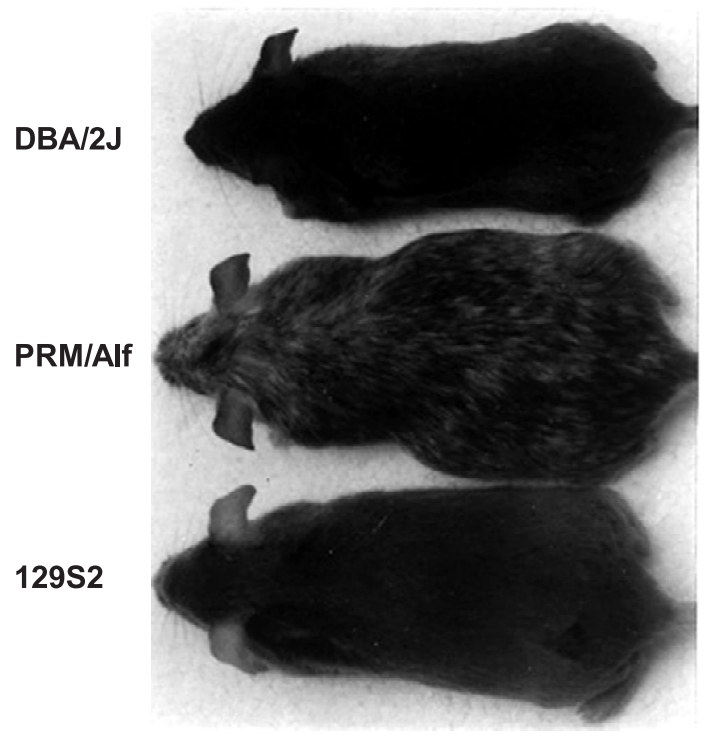

Fig. 1. External morphology of 3-mo-old male mice from DBA/2J, PRM/Alf, and 129S2 inbred strains.

were not significantly different between PRM/Alf and DBA/2J. Proximal colon circumference was significantly increased in $\mathrm{PRM} /$ Alf mice compared with $\mathrm{DBA} / 2 \mathrm{~J}$ mice $(14.8 \pm 1.2$ and $10.9 \pm 0.6 \mathrm{~mm}$, respectively; $P=0.01$, Student's $t$-test). The distal colon circumference was also significantly increased in $\mathrm{PRM} /$ Alf mice compared with DBA/2J mice $(14.7 \pm 0.7$ and $10.0 \pm 0.7 \mathrm{~mm}$, respectively; $P=0.002$, Student's $t$-test).

To search for a possible alteration of the intestinal thickness in PRM/Alf mice, we established a histological picture of the PRM/Alf and DBA/2J intestinal wall. The crypt height was significantly increased in the distal small intestine of PRM/Alf mice compared with DBA/2J mice $(90 \pm 3$ and $74 \pm 4 \mu \mathrm{m}$, respectively; $P<0.0001$, Student's $t$-test) but comparable in the proximal small intestine (Fig. $3 A$ ). The height of villi in the proximal and distal small intestine was similar in both strains (Fig. 3B). The thickness of the mucosa and the submucosa in the proximal and distal parts of the colon showed no significant difference between PRM/Alf and DBA/2J mice (Fig. 3C). The thickness of the tunica muscularis in the proximal and distal parts of the small intestine and the colon was not significantly different between PMR/Alf and DBA/2J mice (Fig. 3D).

Quantitative analysis of ICC distribution. Could the ICC distribution be modified in the lengthened intestine of PRM/Alf mice? To address this question, we made a quantitative analysis of X-gal-positive ICC distribution in the intestine of congenic PRM/Alf-Kit ${ }^{W-l a c Z} /+$ mice. The Kit lacZ knock-in allele has been valuable in the study of $\operatorname{ICC}(5,36)$. We used the $129 \mathrm{~S} 2-\mathrm{Kit}^{\mathrm{W}-\mathrm{lac} Z} /+$ transgenic mouse line as a control. As shown in Fig. 4A, the ICC number was significantly higher in transverse sections of the proximal part of the small intestine in

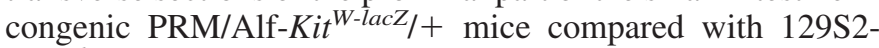
$K_{i t}{ }^{W-l a c Z} /+\operatorname{mice}(111 \pm 22$ and $94 \pm 14$, respectively; $P=$ 0.02 , Student's $t$-test). The ICC number was also significantly higher in the distal part of the small intestine in congenic $\mathrm{PRM} / \mathrm{Alf}-\mathrm{Kit}^{\mathrm{W}-\mathrm{lac} Z} /+$ mice compared with $129 \mathrm{~S} 2-\mathrm{Kit}^{\mathrm{W}-\mathrm{lac} Z} /+$ mice $(111 \pm 26$ and $92 \pm 14$, respectively; $P=0.02$, Student's $t$-test). The difference was striking in transverse sections of the proximal and distal parts of the colon (Fig. 4, $B$ and $C$ ). Indeed, in these regions, the numbers of ICC in congenic PRM/Alf$\mathrm{Kit}^{\mathrm{W}-\mathrm{lac} Z} /+$ mice were almost twice the numbers of ICC seen in $129 \mathrm{~S} 2-K_{i t}{ }^{W-l a c Z} /+$ mice $(569 \pm 95$ vs. $324 \pm 29$ and $219 \pm 47$ vs. $114 \pm 33$ in the proximal and distal colon, respectively; $P<0.0001$, Student's $t$-test). Normalization of ICC number to the intestine circumference showed that an increased circumference did not significantly account for the higher number of ICC in each of the regions (data not shown). Thus the number of ICC in the intestine of congenic PRM/Alf-Kit ${ }^{W-l a c Z} /+$ mice was increased compared with $129 \mathrm{~S} 2-\mathrm{Kit}^{\mathrm{W}-\mathrm{lacZ} /+}$ mice.

Four types of ICC are found in the colon, named by their location (reviewed in Refs. 15 and 30): at the subserosa (ICC-SS), around the myenteric plexus (ICC-MP), in the circular muscle layer (ICC-CM), and at the border between the submucosa and the circular muscle layer, in association with the submuscular plexus (ICC-SMP). In the small intestine, ICC-MP and ICC-DMP are present in the myenteric region and along the deep muscular plexus, respectively. Is the number of ICC uniformly increased among these ICC types in PRM/Alf intestine? To answer this question, the relative distribution of the distinct ICC types was calculated on transverse sections through the wall of specific regions (Fig. 5). In the small intestine of congenic PRM/Alf-Kit ${ }^{W-l a c Z} /+$ and 129S2$\mathrm{Kit}^{\mathrm{W}-\mathrm{lac} Z} /+$ mice, the percentage of ICC-MP decreased from the proximal to the distal regions: from 93 to $61 \%$ in $129 \mathrm{~S} 2-$ $\mathrm{Kit}^{\mathrm{W} \text {-lacZ }} /+$ mice and from 93 to $67 \%$ in congenic PRM/Alf$\mathrm{Kit}^{\mathrm{W}-\mathrm{lac} Z} /+$ mice. The relative percentages of the ICC types were not significantly different between congenic PRM/Alf$K i t^{W-l a c Z} /+$ and $129 S 2-K i t^{W-l a c Z} /+$ mice in the proximal and distal small intestine and in the distal colon [MANOVA, $F$ values (Wilks' lambda) $(2,5)=0.163$ and 0.726 in proximal and distal small intestine, respectively, and $F(4,3)=4.168$ in the distal colon, $P>0.05$ in the 3 regions]. In the proximal colon, the relative percentages of the four types of ICC were significantly different between congenic PRM/Alf-Kit ${ }^{W-l a c Z} /+$ and $129 \mathrm{~S} 2-K_{i} t^{W-l a c Z} /+$ mice [MANOVA, $F(4,3)=28.795$, $P=0.01]$. Indeed, significantly different percentages of ICC-SS and ICC-MP were seen in the proximal colon of congenic PRM/Alf-Kit $t^{W-l a c Z} /+$ mice compared with 129S2$K i t^{W-l a c Z} /+$ mice (univariate $F$-tests, $P<0.05$ ). By contrast,

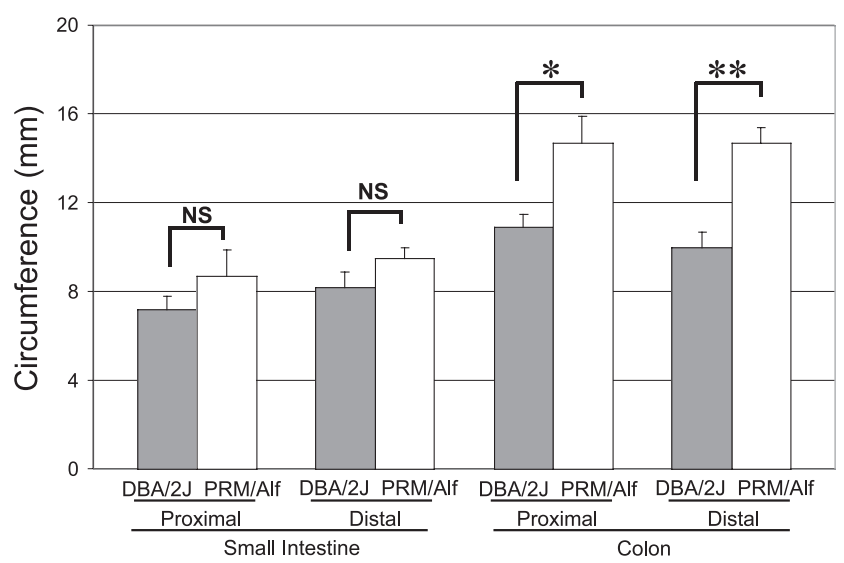

Fig. 2. Comparison of intestine circumference between DBA/2J $(n=3)$ and PRM/Alf mice $(n=4)$. Values are means \pm SE for the given populations. Asterisks indicate the statistical significance of the Student's $t$-test between DBA/2J and PRM/Alf mice: $* 0.01 \leq P<0.05$; **0.001 $\leq P<0.01$. NS, not significant. 

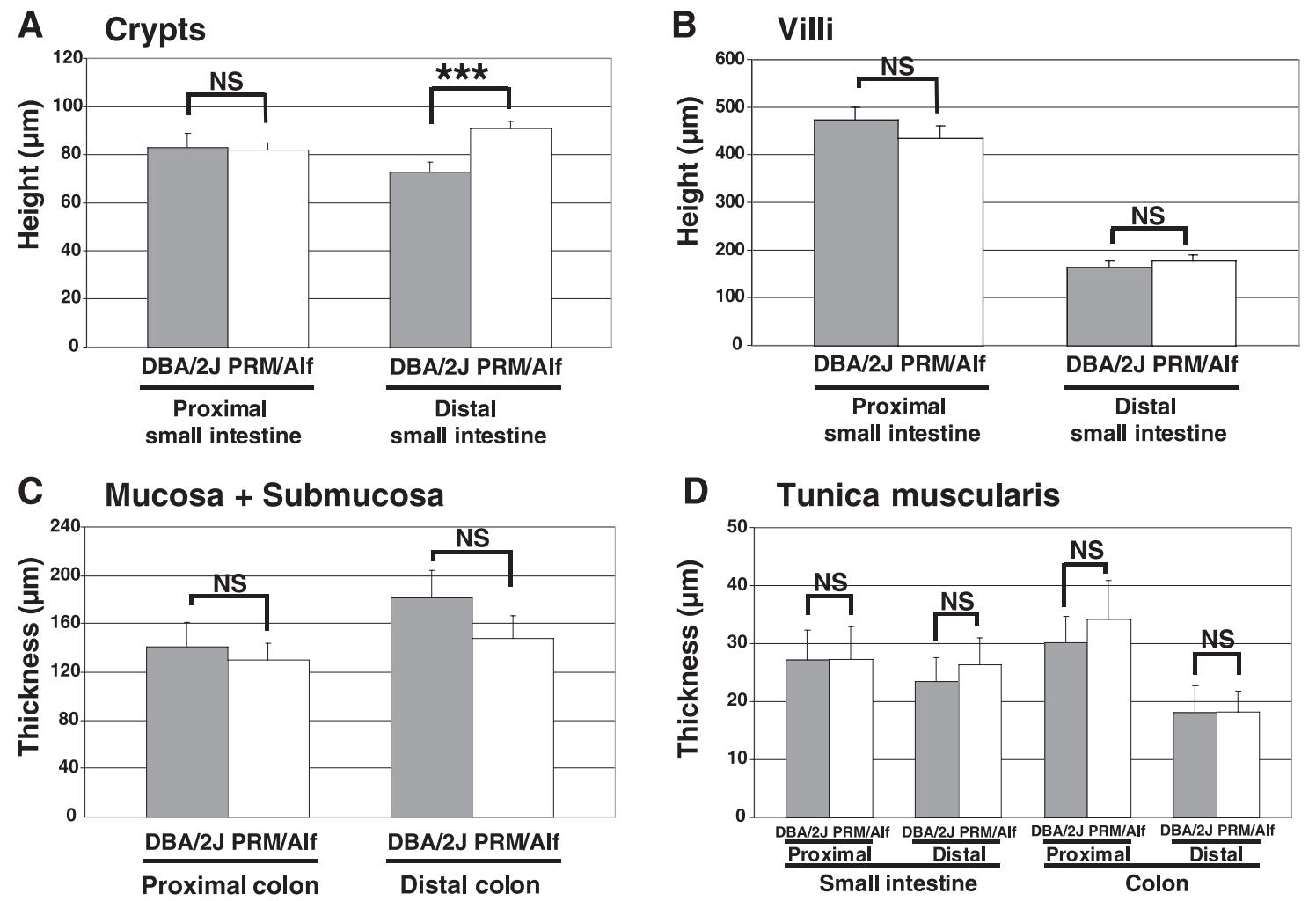

Fig. 3. Morphometric comparison of the layers of the intestinal tract between DBA/2J $(n=3)$ and PRM/Alf $(n=4)$ mice. A: comparison of crypt height in the small intestine epithelium. $B$ : comparison of villi height in the small intestine epithelium. $C$ : comparison of mucosa and submucosa thickness in the colon. $D$ : comparison of tunica muscularis thickness in the small intestine and in the colon. Values are means $\pm \mathrm{SE}$ for the given populations. $* * * P<0.001$ between DBA/2J and PRM/Alf mice (Student's $t$-test).

the percentages of ICC-SMP and ICC-CM in the proximal colon did not differ significantly between congenic PRM/Alf$\mathrm{Kit}^{\text {W-lacZ} /+}$ and $129 \mathrm{~S} 2-\mathrm{Kit}^{\text {W-lacZ } /+}$ mice (univariate $F$-tests, $P>0.05)$. Importantly, the absolute number of ICC-MP in this region was significantly higher in congenic PRM/AlfKit $^{\text {W-lacZ } /+}$ mice compared with $129 \mathrm{~S} 2-$ Kit $^{\text {W-lacZ } /+}$ mice $(216 \pm$ 26 vs. $155 \pm 35$, respectively; $P<0.05$, Student's $t$-test).

Slow-wave frequency in PRM/Alf intestine. Generation of electrical slow waves is an intrinsic property of $\operatorname{ICC}(23,25)$, and regular slow waves occur with the highest frequency in the duodenum (reviewed in Ref. 15). To test whether the increased ICC number in PRM/Alf mice was correlated with a higher slow-wave activity, we compared the spontaneous electrical activity of isolated small intestines from PRM/Alf and DBA/2J mice. Rhythmic variations of resting membrane potentials were recorded from isolated duodenum segments at $37^{\circ} \mathrm{C}$. Slow-wave activity was normal in PRM/Alf isolated duodenums (Fig. 6A), and the slow waves were recorded at a frequency of $53 \pm 3$ cycles/min (Fig. $6 B$ ). In contrast, the frequency of slow waves in isolated duodena from DBA/2J mice was $45 \pm 3$ cycles/min. This $19 \%$ increase of the slowwave frequency in PRM/Alf intestine was highly significant $(P<0.0001$, Student's $t$-test $)$.

Contractility of isolated small intestine segments from PRM/ Alf mice. Intestinal smooth muscle cells contract phasically in response to electrical slow waves (reviewed in Ref. 18). To test the possibility that the intestine contractility could be modified in PRM/Alf mice, we isolated small intestine segments from $\mathrm{PRM} / \mathrm{Alf}$ and DBA/2J mice and measured their contractility ex vivo. Figure $7 \mathrm{~A}$ illustrates plots of the phasic spontaneous longitudinal contractions displayed at $37^{\circ} \mathrm{C}$ by proximal small intestine segments without external stimulation. PRM/Alf proximal small intestines displayed phasic contractions at a regular rate. However, the frequency of proximal small intestine contractions was significantly higher in PRM/Alf mice compared with DBA/2J mice (46 and 39 sweeps/min, respectively; $P=0.04$, Student's $t$-test) (Fig. $7 B$ ).

Gastrointestinal transit time in PRM/Alf mice. The increased contractility of isolated small intestine segments from PRM/ Alf mice could result in an acceleration of the gastrointestinal transit. To test this possibility, we investigated the digestive transit time by using spores of Bacillus subtilis as a physically and chemically inert marker. The mean transit time of Bacillus subtilis spores in PRM/Alf mice was $10.6 \pm 1.5 \mathrm{~h}$. This duration was not statistically different from the mean transit time in DBA/2J mice $(10.3 \pm 1.0 \mathrm{~h} ; P>0.05$, Student's $t$-test $)$ (Fig. 8). An increased gastric emptying in PRM/Alf mice could explain the similar mean transit time despite the important lengthening of their intestine. Thus we determined gastric emptying in PRM/Alf mice. Gastric emptying of semiliquid bolus was not significantly different in $10 \mathrm{PRM} / \mathrm{Alf}$ and 9 $\mathrm{DBA} / 2 \mathrm{~J}$ mice $(55 \pm 11 \%$ in PRM/Alf mice, $58 \pm 9 \%$ in DBA/2J mice; $P>0.05$, Student's $t$-test). Therefore, gastric emptying was not increased in PRM/Alf mice. Together, because PRM/Alf mice had a 30\% longer gastrointestinal tract than DBA/2J mice (3) and an unchanged transit time, the speed of the gastrointestinal transit in PRM/Alf mice was increased compared with $\mathrm{DBA} / 2 \mathrm{~J}$ mice. 


\section{DISCUSSION}

PRM/Alf mice show intestinal lengthening and fast digestive transit. The length of the intestine is genetically controlled in mammals. For instance, when European wild boars were crossed with domesticated Large White pigs, the length of the

\section{A}

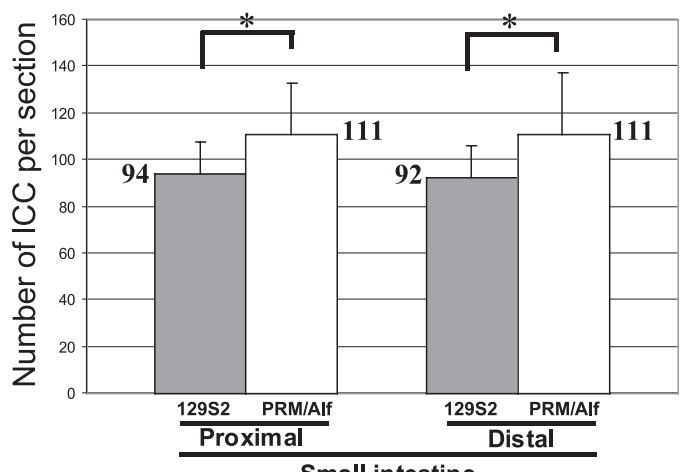

B
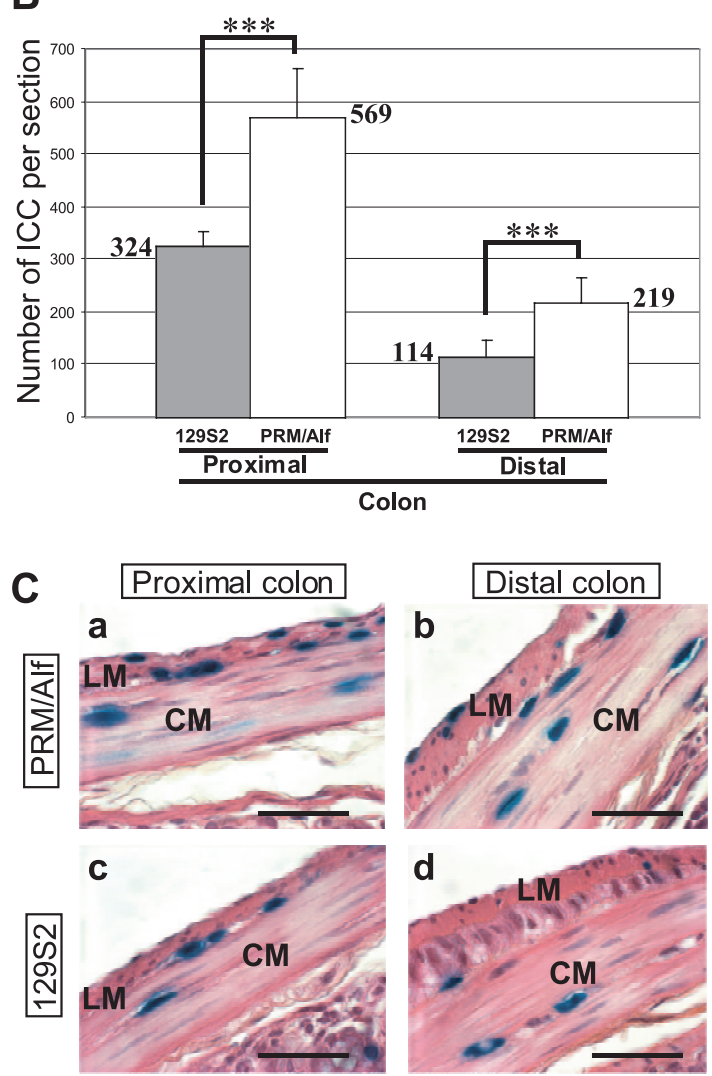

Fig. 4. Interstitial cells of Cajal (ICC) distribution in the small intestine and colon from 129S2-Kit ${ }^{W-l a c Z} /+(n=4)$ and congenic PRM/Alf-Kit ${ }^{W-l a c Z} /+$ $(n=4)$ mice. Quantification of ICC on 5 distant transverse sections per animal are shown. A: proximal and distal small intestine. $B$ : proximal and distal colon. Numbers indicate the actual number of ICC; values are means \pm SE for the given population in the given location. Asterisks indicate the statistical significance of the Student's $t$-test between $129 \mathrm{~S} 2-K_{i} t^{W-l a c Z} /+$ and PRM/Alf-

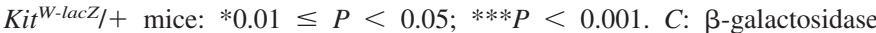
nuclear labeling of ICC on transverse sections of the proximal colon from $\mathrm{PRM} / \mathrm{Alf}-\mathrm{Kit}^{\mathrm{W}-\mathrm{lac} Z} /+(a)$ and $129 \mathrm{~S} 2-\mathrm{Kit}^{W-l a c Z} /+(c)$ mice and in the distal colon from PRM/Alf-Kit $t^{W-l a c Z} /+(b)$ and $129 \mathrm{~S} 2-K t^{W-l a c Z} /+(d)$ mice. LM and CM, longitudinal and circular muscle layers, respectively. Scale bars $=100 \mu \mathrm{m}$.

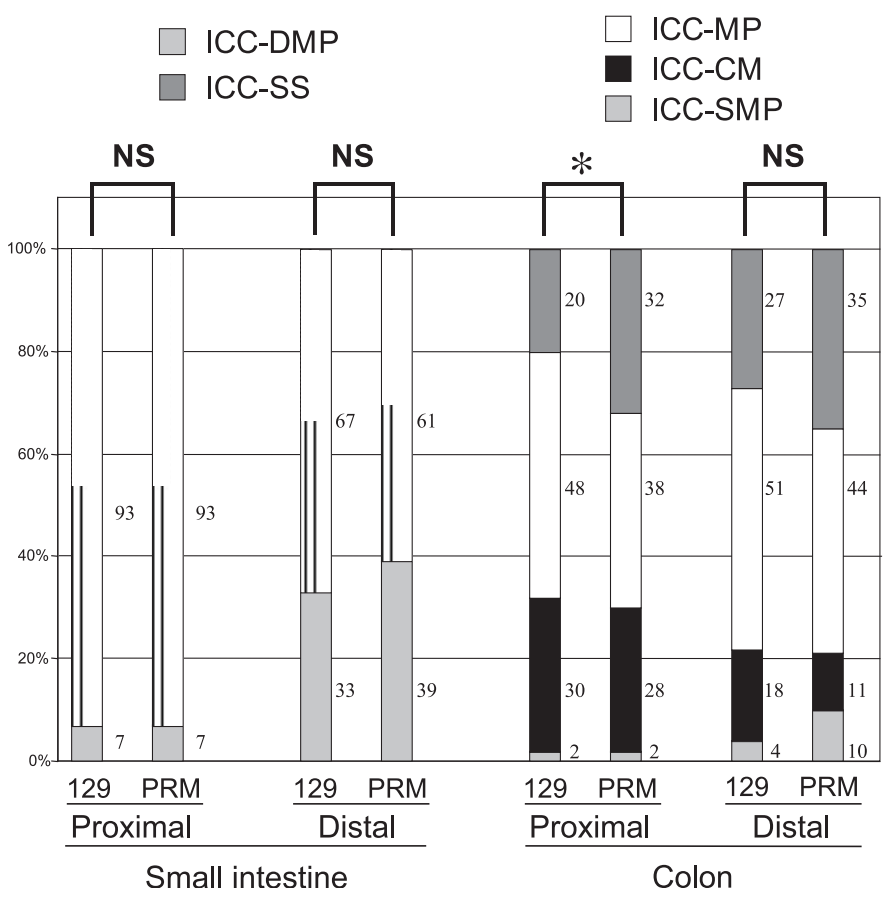

Fig. 5. Distribution of the types of ICC in intestine from 129S2-Kit ${ }^{\text {W-lacZ/+ }}$ $(n=4)$ and congenic PRM/Alf-Kit $t^{W-l a c Z} /+(n=4)$ mice. 129, 129S2$K i t^{W-l a c Z /+}$; PRM, congenic PRM/Alf-Kit ${ }^{W-l a c Z /+}$; ICC-MP, ICC surrounding the myenteric plexus; ICC-DMP, ICC in the region of the deep muscular plexus; ICC-SS, subserosal ICC; ICC-CM, ICC in the circular muscle layer; ICC-SMP, submucosal ICC. Data are given as percentages, calculated as described in MATERIALS AND METHODS. Interpretation of the differences was made by MANOVA, with degrees of freedom involved with the test equal to 2 and 5 in the small intestine and to 4 and 3 in the colon. $* 0.01 \leq P<0.05$. NS, not significant.

small intestine in the F2 progeny was shown to be associated with a quantitative trait locus on chromosome 4 (1). The PRM/Alf strain was derived from a stock originally bred by mouse fanciers. The only selection applied during the inbreeding process was for homozygosity at the patchwork locus

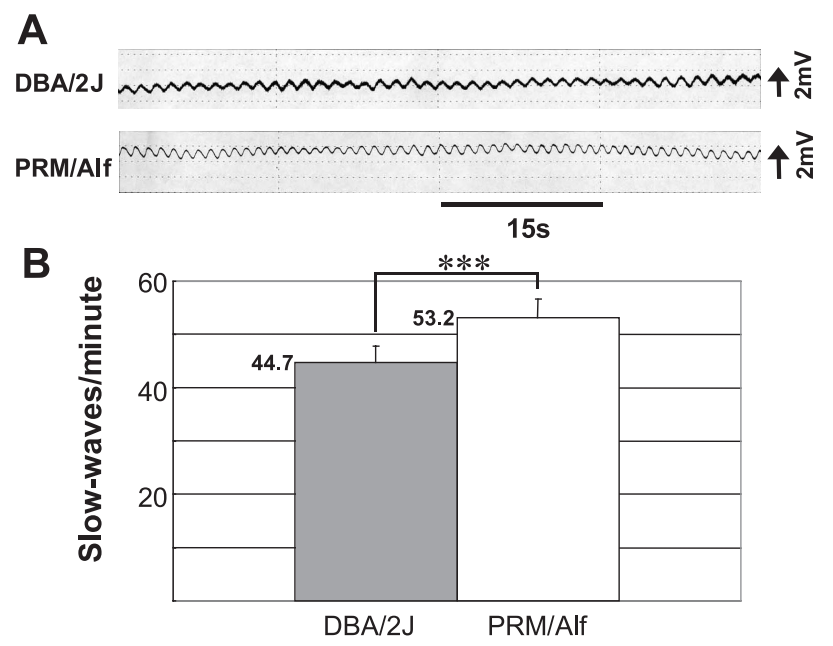

Fig. 6. Slow-wave frequency of isolated duodena from DBA/2J $(n=7)$ and $\mathrm{PRM} / \mathrm{Alf}(n=10)$ mice. $A$ : electrical activity of representative recordings from $\mathrm{DBA} / 2 \mathrm{~J}$ and PRM/Alf mouse duodena. The slow waves are sinusoidal. $B$ : mean frequency of duodenal slow waves in DBA/2J mice and PRM/Alf mice. Values are means $\pm \mathrm{SE}$ for the given population. $* * * P<0.001$ between DBA/2J and PRM/Alf mice (Student's $t$-test). 
A

Fig. 7. Representative tension recordings of isolated duodena from DBA/2J $(n=3)$ and PRM/Alf $(n=3)$ mice. $A$ : patterns of intestine tension from a DBA/2J mouse and a PRM/Alf mouse. $B$ : contraction frequency in DBA/2J mice $(n=3)$ and PRM/Alf mice $(n=3)$. $* 0.01 \leq P<$ 0.05 between DBA/2J and PRM/Alf mice (Student's $t$ test).

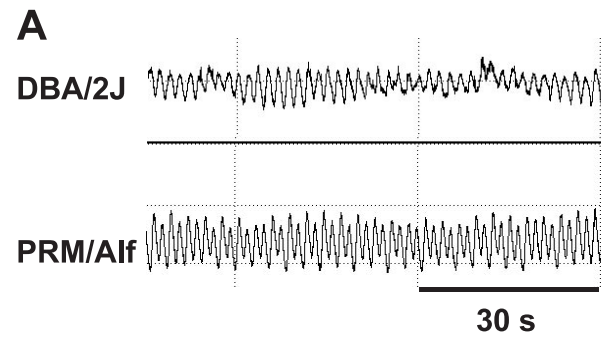

B

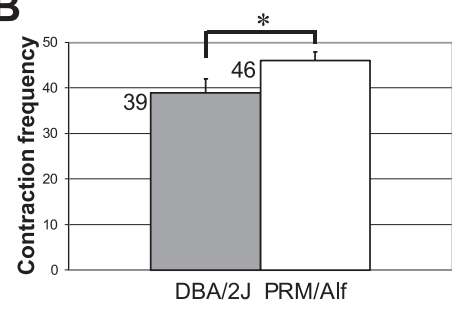

which, when mutated, is responsible for a singular coat color phenotype $(2,4)$. However, the patchwork mutation alone is not responsible for the intestinal phenotype of PRM/Alf inbred mice (3). Indeed, the genetic control of intestine length in $\mathrm{PRM} /$ Alf mice is polygenic and involves a maternal effect (3). The molecular etiology of the intestinal lengthening in PRM/ Alf mice is still unknown; thus it is not possible to establish cause-and-effect relationships between the various features of PRM/Alf intestine described in this study.

$\mathrm{PRM} /$ Alf inbred mice exhibited a $30 \%$ increase in intestine length compared with control DBA/2J mice. The thickness of the intestinal wall was not modified despite a $40 \%$ increase in colonic circumference. Measurements of the tunica muscularis thickness were similar to those previously reported in BALB/c mice (7). By contrast, small intestine lengthening in transgenic mice overexpressing IGF-I locally in smooth muscle cells is associated with increased thickness of the muscular layers (40). Besides these anatomic and histological aspects, the intestinal motility of PRM/Alf mice showed striking alterations. The mean transit time was normal despite the intestine lengthening, indicating accelerated movement of chyme. Moreover, the frequency of ex vivo duodenal contractions at $37^{\circ} \mathrm{C}$ was higher in PRM/Alf mice ( $46 \pm 2 / \mathrm{min})$ compared with $\mathrm{DBA} / 2 \mathrm{~J}$ mice (39 $\pm 3 / \mathrm{min})$. Duodenal contractions are known to occur in vivo at a frequency of $\sim 47 / \mathrm{min}$ in randomly bred mice (10). The lower frequency measured by our assay likely resulted from absence of extrinsic innervation. Indeed, without extrinsic innervation, the enteric nervous system together with the ICC controls smooth muscles coordinated activity. Double immunofluorescence with antibodies specific to ICC (Kit) and neurons (PGP9.5) were realized on whole mount intestines and showed a normal morphology of the myenteric plexuses in the PRM/Alf small intestine (unpublished results).

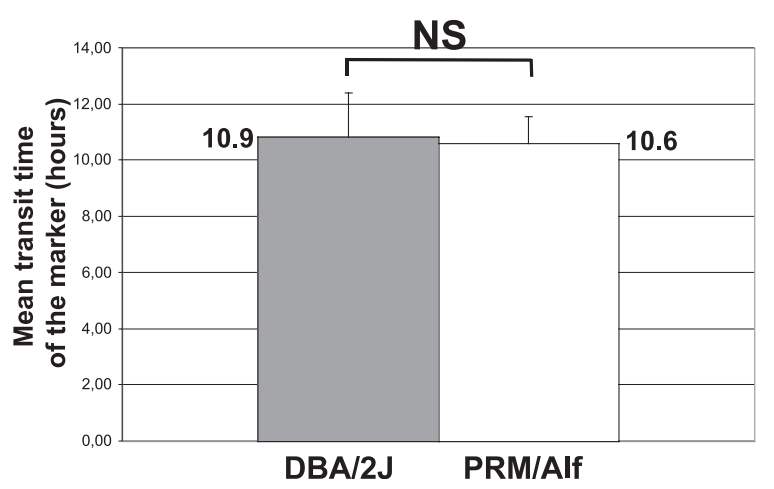

Fig. 8. Comparison of the mean transit times of a gastrointestinal transit marker between DBA/2J $(n=4)$ and PRM/Alf $(n=4)$ mice. The difference observed between DBA/2J and PRM/Alf was not significant.
Slow-wave frequency and the number of ICC are increased in PRM/Alf mice. The slow-wave frequency is species specific and characteristic for each location within the intestine. In C57BL/6 mice, the slow-wave frequency reaches 56 cycles/ min at $0.5 \mathrm{~cm}$ distal from the pylorus and decreases to 45 cycles/min at $5-8 \mathrm{~cm}$ from the pylorus (9). In our experiments, the slow-wave activity was recorded $2 \mathrm{~cm}$ distal to the pylorus and the slow-wave frequency was found to be in the same range of values. As for contractions, the slow-wave frequency in PRM/Alf-isolated duodenums showed an almost $20 \%$ increase compared with DBA/2J (53 and 45 cycles/min, respectively). The slow waves govern the maximal frequency of the muscle contraction in response to excitatory stimuli from the enteric nervous system. A linear relationship may exist between the slow waves and the frequency of the contractions.

It is established that the slow-wave frequency can be modulated. For example, Trichinella spiralis infection causes electrical uncoupling and focal increase in slow-wave frequency, leading to orally propagating contractions that slow the transit in the proximal small intestine (9). In PRM/Alf mice, in vivo video analyses of peristalsis after gavage with barium fluid revealed normal aborally propagating contractions and rapid progression of the barium fluid by comparison with a control strain (data not shown), suggesting that the general control of peristalsis is normal. The number of ICC was significantly higher both in the small intestine and in the colon of congenic PRM/Alf-Kit ${ }^{W-l a c Z} /+$ mice compared with $129 \mathrm{~S} 2-K_{i} t^{W-l a c Z} /+$ mice. The enlargement of the colon in the PRM/Alf strain had only a minor contribution to this increase. Furthermore, all types of ICC were more abundant in the PRM/Alf intestine. To our knowledge, this is the first spontaneous animal model in which an ICC number increase has been observed. This result raises new questions about the relationship between the number of ICC and the frequency of the slow waves. Interestingly, in patients with severe slow-transit constipation, the number of ICC was significantly decreased in all layers of the sigmoid colon (14). The data presented in this study are consistent with the proposal that the rise in the slow-wave frequency in $\mathrm{PRM} /$ Alf mice could be related to the ICC number increase. Conversely, the ICC number increase could be an adaptive response to the faster transit. Indeed, adaptation of the ICC number to physiological modifications may occur; partial obstruction of the gastrointestinal tract induces the disruption of the ICC network, but ICC regenerate when the obstruction is removed (7). Of course, the other partners in the peristaltic contractions (the enteric nervous system and the smooth muscles) could also play a key role in the faster digestive transit. In particular, we cannot exclude that specific subpopulations of enteric neurons might be altered in PRM/Alf intestine. 
Interestingly, hyperplasia of ICC, with 10-20 cell layers instead of 1 or 2 layers in the normal intestine, was observed in the small and large intestines in patients with familial and multiple gastrointestinal stromal tumors (GISTs) (reviewed in Ref. 22). A Val ${ }^{559}$ deletion mutation in the Kit receptor was identified in a human familial GIST case (28). This mutation was recently introduced into the mouse germline by using knock-in gene targeting technology. Mice carrying the engineered mutation showed patchy hyperplasia of Kit-positive cells similar to that of the disease observed in human patients (31). It will be of interest to study the slow-wave activity, contractility, and gastrointestinal transit time in the mutant mice.

The intestine is a single organ composed of cells of various embryological origin combined for performing a vital function: digestion of food. The PRM/Alf inbred strain shows that despite the huge constraints imposed on each of the different cell types, enormous lengthening may happen. However, the transit time in PRM/Alf mice remains unchanged compared with other mice. As François Jacob wrote, "[A]lthough the function brooks no fantasy, the organ preserves some slight degree of freedom" (20).

\section{ACKNOWLEDGMENTS}

We thank Michel Bouchoucha, Philippe Faure, Sylvie Rabot, and Laurent Tiret for critical reading of the manuscript and helpful advice. We are indebted to Sébastien Allix for technical assistance.

\section{GRANTS}

This research was financially supported by the Association pour la Recherche contre le Cancer (contracts 4332 and 99/7468). J. M. Vanderwinden is Senior Research Associate of the National Fund for Scientific Research (Belgium) and was supported by grants from Fondation Médicale Reine Elisabeth (Belgium), Fund for Medical Scientific Research (Belgium), and Fondation Universitaire David et Alice Van Buuren (Belgium).

\section{REFERENCES}

1. Andersson L, Haley CS, Ellegren H, Knott SA, Johansson M, Andresson K, Andersson-Eklund L, Edfors-Lilja I, Fredholm M, Hansson I, Hakansson J, and Lundström K. Genetic mapping of quantitative trait loci for growth and fatness in pigs. Science 263: 1771-1774, 1994

2. Aubin-Houzelstein G, Bernex F, Elbaz C, and Panthier JJ. Survival of patchwork melanoblasts is dependent upon their number in the hair follicle at the end of embryogenesis. Dev Biol 198: 266-276, 1998.

3. Aubin-Houzelstein G, Da Silva NR, Bellier S, Salaun P, Montagutelli $\mathbf{X}$, and Panthier JJ. Genetic interaction between a maternal factor and the zygotic genome controls the intestine length in PRM/Alf mice. Physiol Genomics 16: 82-93, 2003.

4. Aubin-Houzelstein G and Panthier JJ. The patchwork mouse phenotype: implication for melanocyte replacement in the hair follicle. Pigment Cell Res 12: 181-186, 1999.

5. Bernex F, De Sepulveda P, Kress C, Elbaz C, Delouis C, and Panthier JJ. Spatial and temporal patterns of c-kit-expressing cells in WlacZ/+ and WlacZ/WlacZ mouse embryos. Development 122: 3023-3033, 1996.

6. Cannon RA and Cheung AT. Development of methodology for recording colonic myoelectrical activity in the infant primate. Biomater Artif Cells Artif Organs 17: 81-92, 1989.

7. Chang IY, Glasgow NJ, Takayama I, Horiguchi K, Sanders KM, and Ward SM. Loss of interstitial cells of Cajal and development of electrical dysfunction in murine small bowel obstruction. $J$ Physiol 536: 555-568, 2001.

8. Contrepois $\mathbf{M}$ and Gouet $\mathbf{P}$. Utilisation d'une technique microbiologique pour la mesure de la vitesse de transit des microparticules dans le tractus digestif des ruminants. C R Acad Sc Paris 268: 1757-1759, 1969.

9. Der T, Bercik P, Donnelly G, Jackson T, Berezin I, Collins SM, and Huizinga JD. Interstitial cells of Cajal and inflammation-induced motor dysfunction in the mouse small intestine. Gastroenterology 119: 1590$1599,2000$.
10. Der-Silaphet T, Malysz J, Hagel S, Larry Arsenault A, and Huizinga JD. Interstitial cells of Cajal direct normal propulsive contractile activity in the mouse small intestine. Gastroenterology 114: 724-736, 1998.

11. De Winter BY, Bredenoord AJ, De Man JG, Moreels TG, Herman AG, and Pelckmans PA. Effect of inhibition of inducible nitric oxide synthase and guanylyl cyclase on endotoxin-induced delay in gastric emptying and intestinal transit in mice. Shock 18: 125-131, 2002.

12. Drouault S, Anba J, and Corthier G. Streptococcus thermophilus is able to produce a $\beta$-galactosidase active during its transit in the digestive tract of germ-free mice. Appl Environ Microbiol 68: 938-941, 2002.

13. Faussone-Pellegrini MS. Cytodifferentiation of the interstitial cells of Cajal related to the myenteric plexus of mouse intestinal muscle coat. An E M study from foetal to adult life. Anat Embryol (Berl) 171: 163-169, 1985

14. He CL, Burgart L, Wang L, Pemberton J, Young-Fadok T, Szurszewski J, and Farrugia G. Decreased interstitial cell of Cajal volume in patients with slow-transit constipation. Gastroenterology 118: 14-21, 2000.

15. Hirst GDS and Ward SM. Interstitial cells: involvement in rhythmicity and neural control of gut smooth muscle. J Physiol 550: 337-346, 2003.

16. Huizinga JD, Diamant NE, and El Sharkawi TY. Electrical basis of contractions in the muscle layers of the pig colon. Am J Physiol Gastrointest Liver Physiol 245: G482-G491, 1983.

17. Huizinga JD, Thuneberg L, Kluppel M, Malysz J, Mikkelsen HB, and Bernstein A. W/kit gene required for interstitial cells of Cajal and for intestinal pacemaker activity. Nature 373: 347-349, 1995.

18. Huizinga JD, Thuneberg L, Vanderwinden JM, and Rumessen JJ. Interstitial cells of Cajal as targets for pharmacological intervention in gastrointestinal motor disorders. Trends Pharmacol Sci 18: 393-403, 1997.

19. Isozaki K, Hirota S, Miyagawa J, Taniguchi M, Shinomura Y, and Matsuzawa Y. Deficiency of c-kit + cells in patients with a myopathic form of chronic idiopathic intestinal pseudo-obstruction. Am J Gastroenterol 92: 332-334, 1997.

20. Jacob F. In: The Logic of Living Systems: A History of Heredity, translated by Betty E. Spillmann. London: Allen Lane, 1974, chapt. 2, p. 100-101.

21. Kenny SE, Vanderwinden JM, Rintala RJ, Connell MG, Lloyd DA, Vanderhaegen JJ, and De Laet MH. Delayed maturation of the interstitial cells of Cajal: a new diagnosis for transient neonatal pseudoobstruction. Report of two cases. J Pediatr Surg 33: 94-98, 1998.

22. Kitamura Y, Hirota S, and Nishida T. Gastrointestinal stromal tumors (GIST): a model for molecule-based diagnosis and treatment of solid tumors. Cancer Sci 94: 315-320, 2003.

23. Koh SD, Sanders KM, and Ward SM. Spontaneous electrical rhythmicity in cultured interstitial cells of Cajal from the murine small intestine. J Physiol 513: 203-213, 1998.

24. Langer JC, Berezin I, and Daniel EE. Hypertrophic pyloric stenosis: ultrastructural abnormalities of enteric nerves and the interstitial cells of Cajal. J Pediatr Surg 30: 1535-1543, 1995.

25. Lee JC, Thuneberg L, Berezin I, and Huinzinga JD. Generation of slow waves in membrane potential is an intrinsic property of interstitial cells of Cajal. Am J Physiol Gastrointest Liver Physiol 277: G409-G423, 1999.

26. Maeda H, Yamagata A, Nishikawa S, Yoshinaga K, Kobayashi S, and Nishi K. Requirement of c-kit for development of intestinal pacemaker system. Development 116: 369-375, 1992.

27. Mathers JC, Smith H, and Carter S. Dose-response effects of raw potato starch on small-intestinal escape, large-bowel fermentation and gut transit time in the rat. Br J Nutr 78: 1015-1029, 1997.

28. Nishida T, Hirota S, Taniguchi M, Hashimoto K, Isozaki K, Nakamura H, Kanakura Y, Tanaka T, Takabayashi A, Matsuda H, and Kitamura Y. Familial gastrointestinal stromal tumours with germline mutation of the KIT gene. Nat Genet 19: 323-324, 1998.

29. Oozeer R, Goupil-Feuillerat N, Alpert CA, van de Guchte M, Anba J, Mengaud J, and Corthier G. Lactobacillus casei is able to survive and initiate protein synthesis during its transit in the digestive tract of human flora-associated mice. Appl Environ Microbiol 68: 3570-3574, 2002.

30. Sanders KM, Ordog T, and Ward SM. Physiology and pathophysiology of the interstitial cells of Cajal: from bench to bedside. IV. Genetic and animal models of GI motility disorders caused by loss of interstitial cells of Cajal. Am J Physiol Gastrointest Liver Physiol 282: G747-G756, 2002.

31. Sommer G, Agosti V, Ehlers I, Rossi F, Corbacioglu S, Farkas J, Moore M, Manova K, Antonescu CR, and Besmer P. Gastrointestinal stromal tumors in a mouse model by targeted mutation of the Kit receptor tyrosine kinase. Proc Natl Acad Sci USA 100: 6706-6711, 2003. 
32. Spencer NJ, Sanders KM, and Smith TK. Migrating motor complexes do not require electrical slow waves in the mouse small intestine. J Physiol 553: 881-893, 2003.

33. Stoddart CJ and Duthie HL. Effect of vagotomy on the response of gastric myoelectrical activity to glucagon and food. Scand J Gastroenterol 42, Suppl: 77-83, 1976.

34. Tonini M, Costa M, Brookes SJ, and Humphreys CM. Dissociation of the ascending excitatory reflex from peristalsis in the guinea-pig small intestine. Neuroscience 73: 287-297, 1996.

35. Vanderwinden JM, Liu H, De Laet MH, and Vanderhaeghen JJ. Study of the interstitial cells of Cajal in infantile hypertrophic pyloric stenosis. Gastroenterology 111: 279-288, 1996.

36. Vanderwinden JM, Rumessen JJ, Bernex F, Schiffmann SN, and Panthier JJ. Distribution and ultrastructure of interstitial cells of Cajal in the mouse colon, using antibodies to Kit and $\mathrm{Kit}^{\mathrm{W}-\mathrm{lacZ}}$ mice. Cell Tissue Res 302: 155-170, 2000.

37. Vanderwinden JM, Rumessen JJ, Liu H, Descamps D, De Laet MH, and Vanderhaeghen JJ. Interstitial cells of Cajal in human colon and in Hirschsprung's disease. Gastroenterology 111: 901-910, 1996.

38. Ward SM, Burns AJ, Torihashi S, Harney SC, and Sanders KM. Impaired development of interstitial cells and intestinal electrical rhythmicity in steel mutants. Am J Physiol Cell Physiol 269: C1577-C1585, 1995.
39. Ward SM, Burns AJ, Torihashi S, and Sanders KM. Mutation of the proto-oncogene c-kit blocks development of interstitial cells and electrical rhythmicity in murine intestine. J Physiol 480: 91-97, 1994.

40. Williams KL, Fuller CR, Fagin J, and Lund PK. Mesenchymal IGF-I overexpression: paracrine effects in the intestine, distinct from endocrine actions. Am J Physiol Gastrointest Liver Physiol 283: G875-G885, 2002.

41. Yamataka A, Fujiwara T, Kato Y, Okazaki T, Sunagawa M, and Miyano T. Lack of intestinal pacemaker (C-KIT-positive) cells in infantile hypertrophic pyloric stenosis. J Pediatr Surg 31: 96-99, 1996.

42. Yamataka A, Kato Y, Tibboel D, Murata Y, Sueyoshi N, Fujimoto T, Nishiye H, and Miyano T. A lack of intestinal pacemaker (c-kit) in aganglionic bowel of patients with Hirschsprung's disease. J Pediatr Surg 30: 441-444, 1995.

43. Yamataka A, Ohshiro K, Kobayashi H, Fujiwara T, Sunagawa M, and Miyano T. Intestinal pacemaker C-KIT + cells and synapses in allied Hirschsprung's disorders. J Pediatr Surg 32: 1069-1074, 1997.

44. Yamataka A, Ohshiro K, Kobayashi H, Lane GJ, Yamataka T, Fujiwara T, Sunagawa M, and Miyano T. Abnormal distribution of intestinal pacemaker (C-KIT-positive) cells in an infant with chronic idiopathic intestinal pseudoobstruction. J Pediatr Surg 33: 859-862, 1998.

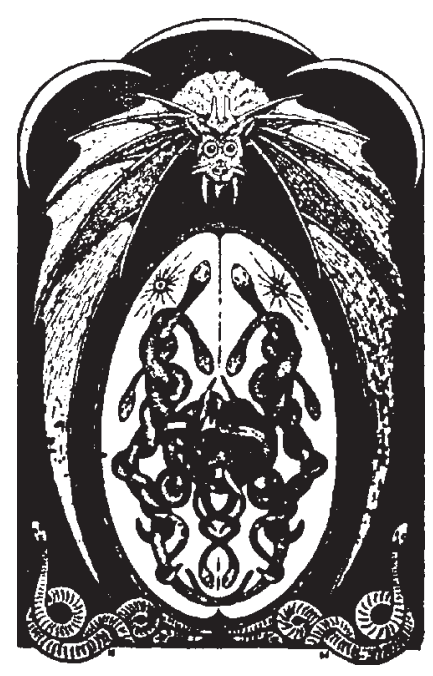

